\title{
EVALUATING CROSTA TECHNIQUE FOR ALTERATION MINERAL MAPPING IN MALANJKHAND COPPER MINES, INDIA
}

\author{
S. Guha ${ }^{1, *}$, H. Govil ${ }^{1}$, M. Tripathi ${ }^{1}$, M. Besoya ${ }^{1}$ \\ ${ }^{1}$ Department of Applied Geology, National Institute of Technology Raipur, Raipur, India- (subhanilguha, himgeo, tripathi.mahesh1, \\ geniousmonika11)@gmail.com
}

Commission V, SS: Natural Resources Management

KEY WORDS: Crosta technique, Landsat, Hydroxyl, Carbonate, Iron oxide

\begin{abstract}
:
Landsat-8 Operational Land Imager (OLI) data has been successfully employed in the field of mineral exploration to detect important minerals. In this study, Crosta technique was applied to identify the diagnostic features of hydroxyl minerals, carbonate minerals and iron oxides in Malanjkhand copper mines, India. The Crosta technique was applied to six [blue, green, red, nearinfrared (NIR), shortwave infrared1 (SWIR1), shortwave infrared2 (SWIR2) bands and two sets of four (blue, red, NIR, SWIR1; and blue, near-infrared, SWIR1, SWIR2) bands of OLI data. Results show that the areas with alteration zones are enhanced much better by using six bands of OLI data. The alteration differences are examined with the Crosta technique using four band combinations. Crosta technique is very useful in generating the images of hydroxyl minerals, carbonate minerals, and iron oxides.
\end{abstract}

\section{INTRODUCTION}

Principal component analysis (PCA) technique is widely considered as an effective technique for alteration mineral mapping (Tangestani and Moore 2001, Ranjbar et al. 2002). The Crosta technique is known as a feature-based selection of principal components. It detects the principal components that contain spectra information about particular minerals using the analysis of eigenvector values. This technique presents the bright or dark pixels in the principal components according to the magnitude and sign of the eigenvectors loadings. This technique can be applied to four and six selected bands of Landsat data (Crosta and Moore 1989, Rutz-Armenta and ProlLedesma 1998).

The objective of this study is to evaluate the Crosta technique for alteration mineral mapping in Malanjkhand area using Landsat-8 OLI data.

\section{MATERIALS AND METHODS}

In this study, cloud-free imageries of Landsat-8 OLI for April 17, 2017 of the study area (path/row 143/45) were freely downloaded from the US Geological Survey (USGS) Earth Resources Observation and Science Center (http://earthexplorer.usgs.gov).

The Crosta technique used here mainly followed the studies of Crosta and Moore (1989), Tangestani and Moore (2000, 2001, 2002) and Torres-Vera and Prol-Ledesma (2003). The Crosta technique or Feature Oriented Principal Components Selection (FPCS) is the analysis of the eigenvector values, which allows identification of the PCs that contain spectral information about specific materials, as well as the contribution of each of the original bands of the components in relation with the spectral response of the materials of interest. This technique also indicates whether the materials are represented by bright or dark pixels in the principal components according with the magnitude and sign of the eigenvectors. The Crosta technique was applied to six non-thermal OLI bands, and to four bands selected on the basis of the spectral characteristics of the hydrothermal minerals and the vegetation.

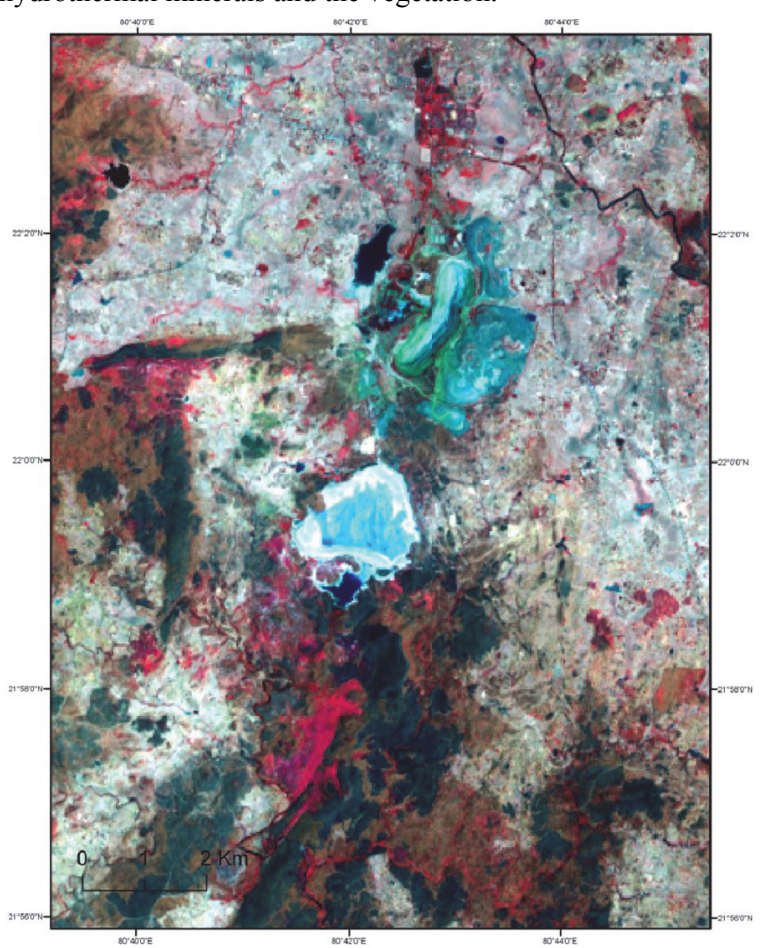

Figure 1: Location of the study area

* Corresponding author 


\section{RESULTS AND DISCUSSION}

Relevant images mapping hydroxyls and iron oxides as bright pixels need inversing as both loadings for SWIR1 in PC5 and NIR in PC5 and PC4 are marked by a negative sign. The PC4s of two separate four-band associations (i.e. blue, red, NIR, SWIR1; and blue, NIR, SWIR1, SWIR2) using Crosta technique primarily hold the information concerning hydroxyls and iron oxides because the greatest loadings were connected to either SWIR1 and SWIR2 or NIR and blue band. Results indicated the false color composites (SWIR2 (red), NIR (green), blue (blue)) overlaid with the remote-sensing anomalies and through Crosta technique using four bands or six bands.

\subsection{Crosta technique using six bands}

The results of the principal component transformation (band load) was described in Table 1, using as input the six OLI bands (OLI-2, OLI-3, OLI-4, OLI-5, OLI-6, and OLI-7) from the Malanjkhand image. It was observed from Table 1 that the first principal component did not contain spectral features relevant in the analysis, as it was a combination of all bands with a major contribution from OLI-6 (68\%). This component contained $87.72 \%$ of the variance of the six bands; hence it gave mainly information about albedo and topography. In the second principal component ( $\mathrm{PC} 2)$, most of the information came from the visible and near-infrared bands. The spectral information of hydroxyls and iron oxide should be contained in PC4, PC5 or PC6; however, the dominant band loads in these components did not correspond to the spectral characteristics of those minerals. Crosta anomalies, pink, red and yellow for hydroxyls, and Cambridge blue, blue and cyan for iron oxides (Figure 2).

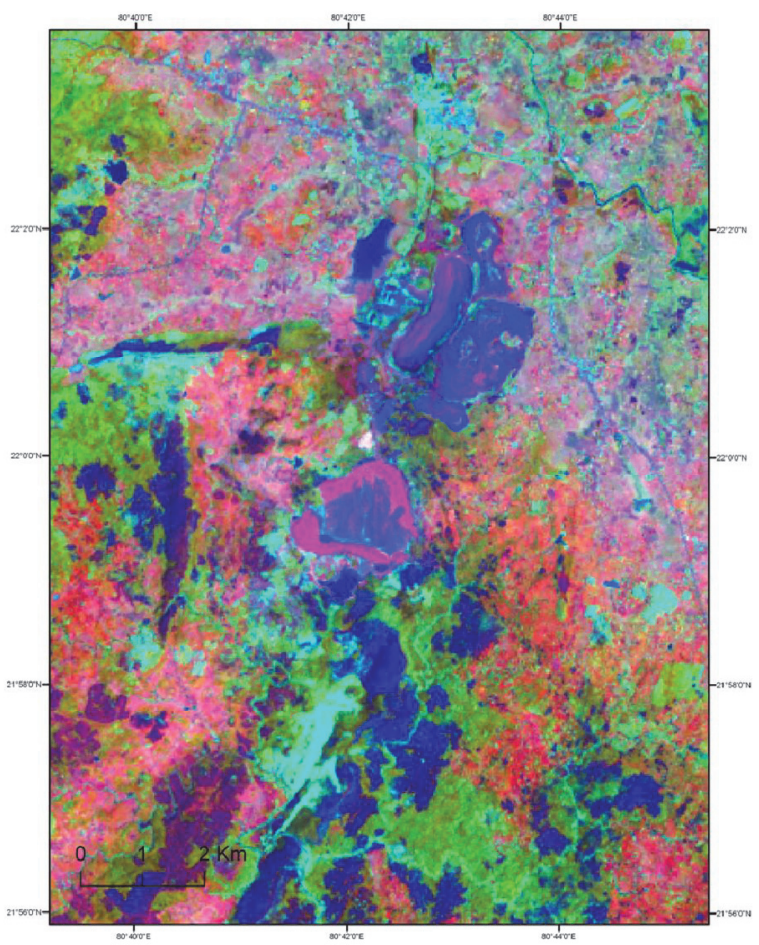

Figure 2. PCA image of six non-thermal OLI bands

\begin{tabular}{|l|l|l|l|l|l|l|}
\hline Eigenvector & PC1 & PC2 & PC3 & PC4 & PC5 & PC6 \\
\hline Band2 & 0.10 & -0.12 & 0.35 & 0.17 & 0.67 & 0.61 \\
\hline Band3 & 0.17 & -0.08 & 0.54 & 0.09 & 0.33 & -0.74 \\
\hline Band4 & 0.28 & -0.14 & 0.55 & 0.36 & -0.65 & 0.22 \\
\hline Band5 & 0.36 & 0.82 & 0.22 & -0.37 & -0.02 & 0.09 \\
\hline Band6 & 0.68 & 0.06 & -0.49 & 0.52 & 0.12 & -0.09 \\
\hline Band7 & 0.54 & -0.52 & -0.05 & -0.65 & -0.04 & 0.06 \\
\hline $\begin{array}{l}\text { \% of } \\
\text { variance }\end{array}$ & 87.72 & 7.06 & 4.49 & 0.56 & 0.15 & 0.03 \\
\hline
\end{tabular}

Table 1. Results of the principal component transformation (band loads) applied to the six non-thermal bands

3.2 Crosta technique using four bands for iron oxide and hydroxyl mapping

The selection of four bands as input for the PCA was based on laboratory spectra of the minerals related with hydrothermal alteration. Mapping of iron oxide was carried out using bands OLI-2, OLI-4, OLI-5, and OLI-6. The analysis for hydroxyl mapping must include bands OLI-2, OLI-5, OLI-6, and OLI-7. The PC band loads for iron oxide mapping were presented in Table 2. The magnitude and sign of the eigenvectors indicated that $\mathrm{PC} 1$ has positive values in all bands, it contained $88.83 \%$ of the data variance, therefore it consisted of albedo and topographic data. PC2 was the representative of the visible bands. The PC4 band loads yield a minimal contribution from OLI-5 and OLI-6 bands (3\% and 6\%, respectively) with respect to OLI-2 and OLI-4 bands ( $86 \%$ and $-50 \%$, respectively); furthermore, the eigenvalues had opposite sign in agreement with the spectral response of the oxide bearing rocks that would be represented as dark pixels. The image shown in Figure 3 was obtained as the PC4 inverse image in order to represent as bright pixels the oxide bearing rocks; however, no good discrimination of oxides was obtained.

\begin{tabular}{|l|l|l|l|l|}
\hline Eigenvector & PC1 & PC2 & PC3 & PC4 \\
\hline Band2 & 0.11 & -0.12 & 0.48 & 0.86 \\
\hline Band4 & 0.32 & -0.22 & 0.77 & -0.50 \\
\hline Band5 & 0.47 & 0.88 & 0.07 & 0.03 \\
\hline Band6 & 0.82 & -0.40 & -0.41 & 0.06 \\
\hline \% of variance & 88.83 & 6.44 & 4.55 & 0.19 \\
\hline
\end{tabular}

Table 2. Principal component band load for iron oxide mapping (analyzed bands OLI-2, OLI-4, OLI-5, and OLI-6) 


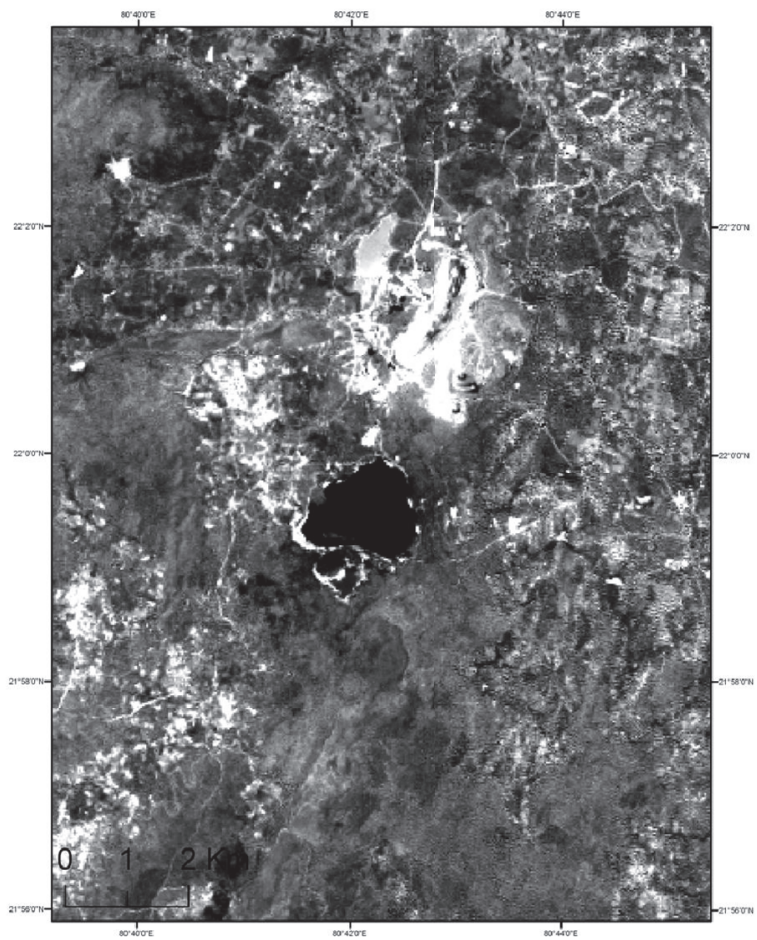

Figure 3. PC4 inverse image that resulted from the Crosta technique applied to bands OLI-2, OLI-4, OLI-5, and OLI-6, where bright pixels represent the oxide-bearing rocks.

The results of the principal component analysis including OLI2, OLI-5, OLI-6, and OLI-7 bands to map hydroxyl-bearing minerals were given in Table 3. The bands were chosen to take into account the spectral characteristics of the hydroxyl-bearing minerals, and OLI-3 and OLI-4 bands were omitted to avoid mapping iron oxide. In the similar procedure applied in the oxide analysis, the eigenvector loading for PC1, PC2, and PC3 yield analogous results. The eigenvector loading for PC4 shows a large negative value for OLI-7 (45\%) and a positive value for OLI-6 (36\%). These values significantly correlated with the spectral response for hydroxyl; therefore, the inverse image of PC4 should present the areas with high hydroxyl concentrations as bright pixels (Figure 4). It was observed that some areas gave a sharp response but large areas also had a high brightness value that should be taken into account.

\begin{tabular}{|l|l|l|l|l|}
\hline Eigenvector & PC1 & PC2 & PC3 & PC4 \\
\hline Band2 & 0.10 & -0.08 & 0.60 & 0.79 \\
\hline Band5 & 0.38 & 0.83 & 0.33 & -0.21 \\
\hline Band6 & 0.72 & -0.01 & 0.59 & 0.36 \\
\hline Band7 & 0.57 & -0.55 & 0.42 & -0.45 \\
\hline \% of variance & 89.80 & 7.93 & 1.80 & 0.40 \\
\hline
\end{tabular}

Table 3. Principal component band load for hydroxyl mapping (analyzed bands OLI-2, OLI-5, OLI-6, and OLI-7)

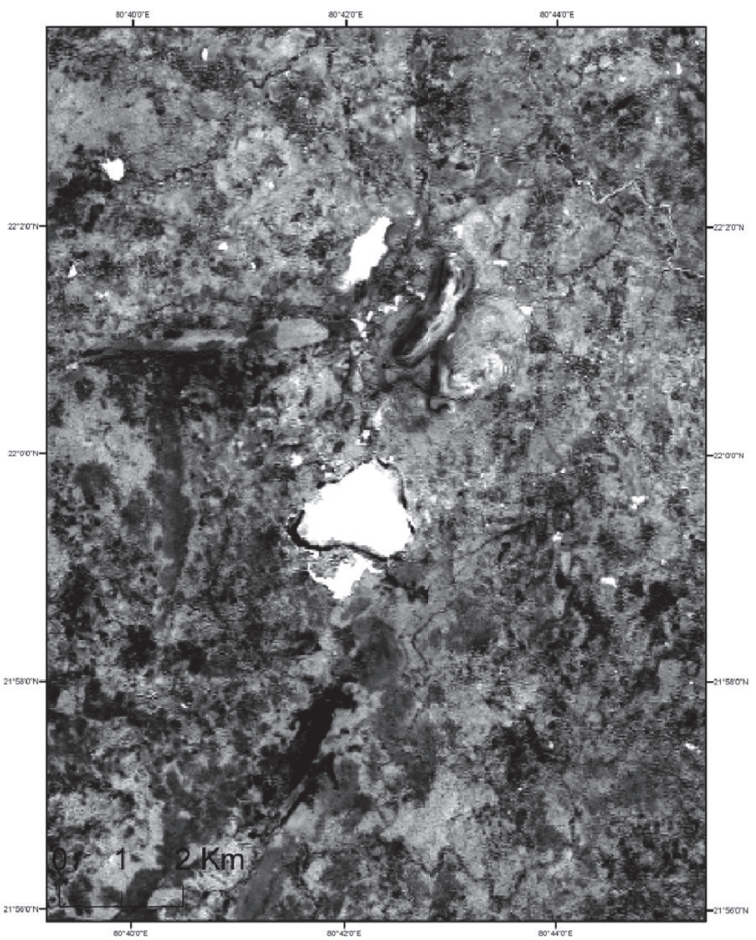

Figure 4. Results of the Crosta technique applied to bands OLI2, OLI-5, OLI-6, and OLI-7, where PC4 is shown as bright pixels the hydroxyl-bearing rocks.

In the light of all the results, it can be concluded that the Crosta technique is effective in determining the alteration types, using six or selected four Landsat OLI bands. The analysis performed using four Landsat OLI bands were found to be a less effective differentiator than the analysis using the six Landsat OLI bands.

\section{CONCLUSION}

The present study focused on the effectiveness of Crosta technique in alteration mineral mapping using Landsat OLI datasets in Malanjkhand copper mines of Madhya Pradesh, India. Crosta technique is very useful in detecting hydroxylmineral, carbonate mineral, and iron oxides. The present study analyzed that the Crosta technique was more effective with six non-thermal Landsat-8 OLI bands combination. The results were significantly comparable to the published geological map.

The Crosta technique relies on the PC transform to map information common to all bands - overall Scene brightness or albedo - into the first principal component and specific spectral contrasts into successive components. The simple methodology for hydroxyl mapping by PCA on OLI bands 2, 5, 6, and 7 was to examine the eigenvector loadings for bands 6 and 7 to find a moderate or strong loading from both bands with opposite signs. Carrying out the PCA on unstretched bands of Malanjkhand area enhances the hydroxyl bearing area in PC4 as dark pixels. The enhancement was unique for hydroxyl without any kind of presence of vegetation. If the PCA is carried out on the stretched images, the vegetation area will also be enhanced in dark pixels. Standard principal component analysis, however, enhanced the alteration areas in one of the PCAs but was a time-consuming procedure and all the PCA images must be examined to find the alteration PC. Using the thermal band of OLI in transformation only shifts the alteration PC from PC5 to 
PC6. Thus, the hydroxyl mapping technique of Crosta methodology was suggested for alteration mapping in Malanjkhand copper mining area, India.

\section{ACKNOWLEDGEMENTS}

Authors are thankful to United States Geological Survey (USGS)

\section{REFERENCES}

Crosta, A., Moore, J.McM. 1989. Enhancement of Landsat thematic mapper imagery for residual soil mapping in SW Minais Gerais State, Brazil: a prospecting case history in Greenstone belt terrain. In: Proceedings of 7th ERIM Thematic Conference: Remote sensing for exploration geology, pp. 11731187

Ranjbar, H., Honarmand, M., Moezifar, Z., Ilaghi, O. 2002. Integration and analysis of remote sensing, airborne geophysics and geochemical data of Shar Cheshmeh area, using directed principal component analysis. In: 9th International Remote Sensing Conference, Agia Pelagia, Greece, 23-26 September, pp. 429-437.

Rutz-Armenta, J.R., Prol-Ledesma, R.M. 1998. Techniques for enhancing the spectral response of hydrothermal alteration minerals in Thematic Mapper images of Central Mexico. International Journal of Remote Sensing,19, pp. 1981-2000

Tangestani, M.H., Moore, F. 2000. Iron-Oxide and Hydroxyl Enhancement Using the Crosta Method; A Case Study from the Zagros Belt, Fars Province, Iran. ITC Journal, in press.

Tangestani, M.H., Moore, F. 2001. Comparison of three principal component analysis techniques to porphyry copper alteration mapping. A case study, Meiduk area, Kerman, Iran. Canadian Journal of Remote Sensing, 27, pp. 176-182

Tangestani, M.H., Moore, F. 2002. Porphyry copper alteration mapping at the Meiduk area, Iran. International Journal of Remote Sensing, 23, pp. 4815-4825

Torres-Vera, M.A., Prol-Ledesma, R.M. 2003. Spectral enhancement of selected pixels in Thematic Mapper images of the Guanajuato district (Mexico) to identify hydrothermally altered rocks. International Journal of Remote Sensing, 24, pp. $4357-4373$ 